\section{Air Quality of a Hospital after Closure for Black-Water Flood: An Occupational- Health Concern?}

To the Editor-The monitoring of air quality in hospitals is essential in order to minimize occupational risk to healthcare workers (HCWs) and to enhance patient safety. ${ }^{1}$ Exposure to particles of less than $10 \mu \mathrm{m}$ can exacerbate wheezing, asthma, and respiratory infections. ${ }^{2}$ Exposure to excess carbon monoxide can induce tachypnea and reduce oxygen delivery to key organs, inclusive of developing fetuses. ${ }^{2,3}$ Excess humidity has been associated with the growth of fungus, and the sickbuilding syndrome is generally reported for persons from a building in which complaints of ill health are more common. ${ }^{4}$ Limited data exist for hospital indoor air quality after extensive black-water floods. We report the findings from initial indoor air quality measurement after extensive black-water floods led to closure of a tertiary care hospital in central Thailand.

Thammasat University Hospital was closed on October 14, 2011, as a result of progressive black-water flooding of the ground floor that reached a peak height of $3 \mathrm{~m}$; the hospital reopened on December 12, 2011. All 68 patient care areas in 18 hospital units were assessed for indoor air quality within 72 hours of the hospital's reopening. The assessment included carbon dioxide, carbon monoxide, humidity, and temperature and used the Q-Trak Indoor Air Quality Monitor (TSI); bacterial and fungal air bioburden measures used MAS 100NT (Merck). Carbon dioxide was measured at a median of 850 ppm (range, 540-939 ppm; reference, $<1,000 \mathrm{ppm}$ ), median carbon monoxide was $0 \mathrm{ppm}$ (range, $0 \mathrm{ppm}$; reference, $<9$ $\mathrm{ppm}$ ), median relative humidity $(\mathrm{RH})$ was $68 \%$ (range, $57 \%-69 \%$; reference, $30 \%-60 \%$ ), and median temperature was $24.9^{\circ} \mathrm{C}$ (range, $20^{\circ}-29.6^{\circ} \mathrm{C}$; reference, $20^{\circ}-26^{\circ} \mathrm{C}$ ). The me- dian total bacterial and fungal bioburdens were 654 colonyforming units $(\mathrm{CFU}) / \mathrm{m}^{3}$ (range, $120-8,360 \mathrm{CFU} / \mathrm{m}^{3}$; reference, $<500 \mathrm{CFU} / \mathrm{m}^{3}$ ) and $590 \mathrm{CFU} / \mathrm{m}^{3}$ (range, $160-4,400$ $\mathrm{CFU} / \mathrm{m}^{3}$; reference, $<500 \mathrm{CFU} / \mathrm{m}^{3}$ ), respectively. ${ }^{5}$ All hospital units passed the initial air quality standard for carbon dioxide and carbon monoxide. However, 36 of 68 rooms (53\%) had humidity measurements within normal limits, 46 rooms (67\%) had temperature measurement within normal limits, and 23 rooms ( $34 \%$ ) had both bacterial and fungal bioburden levels greater than $500 \mathrm{CFU} / \mathrm{m}^{3}$. Indoor air quality measurements were different for open- and closed-ventilation patient care areas (Table 1). Bacterial and fungal bioburden levels greater than $500 \mathrm{CFU} / \mathrm{m}^{3}$ were detected only on units with excess humidity $(100 \%$ [23/23] vs $0 \%[0 / 45] ; P<.001)$. All areas ( $N=6$ separate patient care areas) previously reported for fungal pseudo-outbreaks had excess humidity as well as high bacterial and fungal bioburden. ${ }^{4}$ By multivariate analysis, first-floor units were associated with high bacterial and fungal bioburden (adjusted odds ratio, 1.16 [95\% confidence interval, 1.09-66.9]).

Our findings suggest that extensive black-water flooding had a significant impact on the hospital's postflood air quality, particularly in the units that had excess humidity. Hospital administration should consider a delay in reopening units until indoor air quality has returned to normal. Serial monitoring of the hospital indoor air quality and creation of a policy to expedite mask use for HCWs and patients in highrisk areas associated with bacterial and fungal bioburden are relevant interventions to minimize occupational risks to HCWs and optimize patient safety during the postflood period. Additional studies to follow up on long-term HCW and patient health after exposure to units reopened after blackwater flood exposure are needed to optimize resource allocation and safety.

TABLE 1. Air Quality Characteristics Assessed after Reopening 68 Patient Care Areas of 18 Hospital Units That Were Closed after Excess Black-Water Flooding in Central Thailand

\begin{tabular}{|c|c|c|c|c|}
\hline Air quality characteristics & $\begin{array}{l}\text { All rooms } \\
(N=68)\end{array}$ & $\begin{array}{l}\text { Open-ventilation } \\
\text { patient care areas } \\
\qquad(N=39)\end{array}$ & $\begin{array}{l}\text { Closed-ventilation } \\
\text { patient care areas } \\
\qquad(N=29)\end{array}$ & $P$ value \\
\hline Median relative humidity, $\%$ (range) & $60.9(56.9-72.4)$ & $60.3(57.3-72.4)$ & $61.6(56.9-71.9)$ & .24 \\
\hline Median temperature, ${ }^{\circ} \mathrm{C}$ (range) & $26.6(20.0-28.6)$ & $27.6(25.5-28.6)$ & $25.9(20.0-28.2)$ & .001 \\
\hline Median carbon dioxide, ppm (range) & $537.5(492.0-707.0)$ & $524.0(504.0-594.0)$ & $554.0(492.0-707.0)$ & .09 \\
\hline Median bacterial bioburden, CFU $/ \mathrm{m}^{3}$ (range $)^{\mathrm{c}}$ & $654(120-8,360)$ & $880(140-8,360)$ & $475(120-1,980)$ & .04 \\
\hline 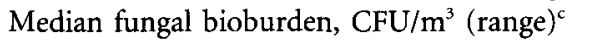 & $590(160-4,400)$ & $775(200-4,400)$ & $430(160-2,680)$ & .05 \\
\hline
\end{tabular}

NOTE. A $\chi^{2}$ or Fisher exact test was used to compare categorical data, as appropriate. Continuous variables were compared with a Mann-Whitney $U$ test. Boldface indicates that results are statistically significant, at $P \leq .05$. CFU, colony-forming unit.

a Open-ventilation area was defined as using natural air for ventilation.

b Closed-ventilation area was defined as using an air-conditioning system for ventilation.

c Bacterial and fungal bioburden was measured twice in each area and mean total respective bioburden per unit was calculated. 


\section{ACKNOWLEDGMENTS}

Financial support. This study was supported by the National Research University Project of the Thailand Office of Higher Education Commission (A.A., T.K.).

Potential conflicts of interest. L.M.M. reports that she is an employee of GlaxoSmithKline and that this work was conducted pro bono and independently of such employment. All other authors report no conflicts of interest relevant to this article. All authors submitted the ICMJE Form for Disclosure of Potential Conflicts of Interest, and the conflicts that the editors consider relevant to this article are disclosed here.

\section{Anucha Apisarnthanarak, $\mathrm{MD}^{1}$ Thana Khawcharoenporn, MD, MSc; Linda M. Mundy, $\mathrm{MD}, \mathrm{PhD}^{2}$}

\begin{abstract}
Affiliations: 1. Division of Infectious Diseases, Faculty of Medicine, Thammasat University Hospital, Pathumthani, Thailand; 2. Bryn Mawr, Pennsylvania.

Address correspondence to Anucha Apisarnthanarak, MD, Division of Infectious Diseases, Faculty of Medicine, Thammasat University Hospital, Pathumthani, Thailand 12120 (anapisarn@yahoo.com).

Infect Control Hosp Epidemiol 2012;33(12):1285-1286

(C) 2012 by The Society for Healthcare Epidemiology of America. All rights reserved. 0899-823X/2012/3312-0024\$15.00. DOI: $10.1086 / 668445$
\end{abstract}

\section{REFERENCES}

1. Samet JM, Spengler JD. Indoor environments and health: moving into the 21 st century. Am J Public Health 2003;93(9):1489-1493.

2. Bruce N, Perez-Padilla R, Albarak R. Indoor air pollutions in developing countries: a major environmental and public health challenge. Bull World Health Organ 2000;78(9):1078-1092.

3. Centers for Disease Control and Prevention (CDC). Exposure to nitrogen dioxide in an indoor ice arena-New Hampshire, 2011. MMWR Morb Mortal Wkly Rep 2012;61(8):139-142.

4. Apisarnthanarak A, Khawcharoenporn T, Mundy LM. Blackwater floods and hospital-based postflood mold investigations. Infect Control Hosp Epidemiol 2012;33(12):1266-1268.

5. Institute of Environmental Epidemiology, Ministry of the Environment of Singapore. Guidelines for good indoor air quality in office premises. http://app2.nea.gov.sg/data/cmsresource 120081211230487457774.pdf. Accessed February 14, 2012.

\section{Variability of Adenosine Triphosphate- Based Bioluminescence Assay Readings among Drug-Resistant Pathogens}

To the Editor-Environmental contamination of clinically relevant drug-resistant organisms (eg, methicillin-resistant Staphylococcus aureus [MRSA], Clostridium difficile, vancomycin-resistant enterococci [VRE], and extended-spectrum $\beta$-lactamase [ESBL]-producing and Klebsiella pneumoniae carbapenemase $[\mathrm{KPC}]$-producing gram-negative bacteria) frequently occurs and may contribute to their transmission in the healthcare setting. ${ }^{1-3}$ The Centers for Disease Control and Prevention has recommended that hospitals ensure com- pliance by housekeeping staff with cleaning and disinfection procedures. ${ }^{4}$ Monitoring systems have been developed to determine the effectiveness of hospital cleaning procedures. ${ }^{5}$ One such system utilizes the detection of adenosine triphosphate (ATP) on surfaces. ATP is a compound used in the metabolic processes of cells and, therefore, is present in all organic material. The detection of ATP on environmental surfaces in hospitals has been used to assess the adequacy of routine cleaning procedures, with a proposed cutoff value of less than 250 relative light units (RLUs) for a thoroughly cleaned surface. ${ }^{6,7}$ This study aimed to determine whether differences in detectability based on ATP readings of epidemiologically significant organisms, including drug-resistant pathogens, can be found.

An ATP bioluminescence assay, the AccuPoint HC system (Neogen), was used to assess differences among 9 known bacterial strains obtained from the American Type Culture Collection (ATCC)-namely, MRSA (ATCC 43300), VRE (ATCC 51299), Pseudomonas aeruginosa (ATCC 27853), Escherichia coli (ATCC 25922), Klebsiella pneumoniae (ATCC 38657), KPCproducing K. pneumoniae (ATCC BAA-1705), ESBL-producing $K$. pneumoniae (ATCC 700603), C. difficile vegetative form (ATCC 43255), and C. difficile spores (ATCC 43255). These were prepared to an approximate concentration of $1.5 \times 10^{6} \%$ $10 \mu \mathrm{L}$. For each bacterial strain, four $1: 10$ serial dilutions were made from the base suspension. ATP readings were then taken from the base suspension and from each dilution by inoculating $10 \mu \mathrm{L}$ onto the ATP swab. Ten replicates were done for each concentration. Ten-microliter samples from each dilution of organisms were grown to determine the viability of the organisms and the accuracy of the dilution process.

Our results (Table 1) showed that the ATP readings were proportional to the concentration values for MRSA, VRE, and $P$. aeruginosa. With concentrations of $1.5 \times 10^{6} / 10 \mu \mathrm{L}$, ATP readings were highest, and these declined proportionately to the $1.5 \times 10^{2} / 10 \mu \mathrm{L}$ values. This is a validation of the bacterial concentration. KPC-producing $K$. pneumoniae and $C$. difficile spores were undetected at any concentration. For E. coli, K. pneumoniae, and ESBL-producing K. pneumoniae, values were detectable only at the highest concentration $\left(1.5 \times 10^{6} / 10 \mu \mathrm{L}\right)$; for vegetative $C$. difficile, values were detectable only at the highest 2 concentrations $\left(1.5 \times 10^{6} / 10\right.$ $\mu \mathrm{L}$ and $1.5 \times 10^{5} / 10 \mu \mathrm{L}$ ).

It is clear from these data that for KPC-producing $K$. pneumoniae and $C$. difficile spores, no concentration examined yielded measurable ATP values. For the remaining 7 bacteria, a simple analysis of variance was conducted with the highest concentration to verify the clear differences among the different bacteria. The differences were significant among the pathogens with measurable ATP readings $(F=41.3$, $P \leq .001$ ).

We demonstrated differences in detectability and ATP readings of the organisms studied. A value of 250 RLUs has been proposed by previous studies as thoroughly "clean." ever, this standard may need to be assessed further for eval- 